Spatial Demography 2013 1(1): 120-130

http://spatialdemography.org

OPEN ACCESS

via Creative Commons 3.0

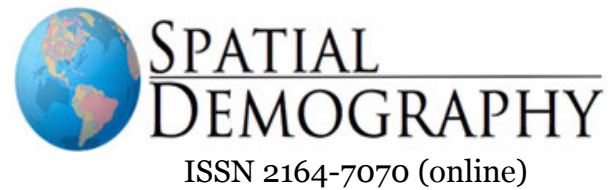

ISSN 2164-7070 (online)

\title{
COLUMN
}

\section{What are Spatial Data? When are They Sufficient?}

\author{
Lee R. Mobley \\ Editor, Spatial Data
}

Spatial data are data describing places or things. Spatial data are spatially sufficient when they contain enough detail to fully characterize the places or things that they represent. Thus they are spatially representative of the constructs they represent. For example, spatial data used for demographic research are spatially representative when they are fully representative of the populations within the places studied. Spatially representative data for topographical or environmental research are fully representative of the terrain or biological or natural features within the places studied. Population-based samples, such as the US census of Populations data products, are good examples of spatially representative data for spatial demography research.

Some examples of data that are not spatially representative may help clarify what exactly we mean by spatially sufficient data. Climate or air quality data collected from a geographically sparse set of monitoring stations do not provide spatiallyrepresentative climate or air quality data for all places. These data are samples, with geographic addresses, but don't reflect all places and can't be generalized to reflect all places accurately. Smoothing over these climate data using spatial interpolation methods to fill in the gaps, providing data where there aren't monitoring stations, is prone to error. Wind patterns, topographic features, and natural features (lakes, rivers) affect air currents and climate data in ways not captured by uniform smoothing algorithms. By contrast, grid or raster data provided by satellite imagery to completely characterize land cover at a very fine spatial scale are spatially representative data.

From a demographic perspective, survey sample data are examples of data that are not necessarily spatially representative. If the survey was designed to fully characterize populations within certain geographic units, then they are spatially representative of populations in those geographic units. For example, the Behavioral Risk Factor Surveillance System (BRFSS) was designed to represent populations in states, and is spatially representative of health behaviors in the state-level populations. Some states, such as Illinois, Florida, and South Carolina, have taken the initiative to provide funding for oversampling so that every county in the state is wellrepresented. For these states, the BRFSS data are spatially representative at the county level, but for the vast majority of states, BRFSS data are spatially representative at the state level only. The survey collects information from respondents regarding their county of residence, but having this information on file does not necessarily mean that the data are representative of counties. This feature is common to other national health surveys, and the purpose of this article is to make users aware of the hazards of improperly interpreting or over-generalizing findings geocoded to smaller scales than supported by the sampling methodology.

Non-spatially representative data have limitations, and these should be recognized. It is important to employ critical spatial thinking before embarking on analyses using data with geographic identifiers. The most important 
consideration is whether the data are spatially representative of the geographic scales at which conclusions are drawn from the research. The following example illustrates the problems that arise when data are over-generalized beyond the spatial support they provide.

Recent efforts by the Centers for Disease Control and Prevention (CDC) have focused on using the small, survey-based BRFSS to identify areas in greatest need of diabetes intervention. Barker et al (2011) used CDC's predicted diabetes prevalence data (CDC, 2009; 2012) to identify 644 high-risk counties in a wide "diabetes belt" across the Southeast. Based on the study's findings and prescriptions, investments in diabetes control interventions and infrastructure are apparently needed in more than $25 \%$ of U.S. counties. However, the BRFSS sample on which the Barker et al. (2011) study was based was not designed to be a spatially representative sample of county populations. The sample sizes in many counties are too small to produce direct estimates of local outcomes, and about $25 \%$ of counties are not represented at all (Frazier et al., 1992).

In Exhibit 1, we reproduced the diabetes belt graphic from Barker et al. (2011, Figure 2) using CDC's predicted diabetes prevalence data (CDC, 2012). In the right panel, we show the actual BRFSS survey data sample sizes for 2007-2008 on which the predicted diabetes prevalence estimates were based, overlaid with the diabetes belt from Barker et al (2011). Areas with more than 50 sample observations are deemed spatially representative, based on CDC's recommendations, and are colored in gold. Areas with some data but less than 50 observations in the pooled years is colored grey, and areas with no data are colored white.

It is evident that large patches of the predicted diabetes belt are supported by very little spatial data. It is particularly troubling that the wide swath of the predicted belt across the state of Georgia was based on so little sample information. The Atlanta metropolitan area, with large samples, was not included in the belt. South

Exhibit 1. The Predicted Diabetes Belt, and Sample Sizes in Counties Used for the Prediction
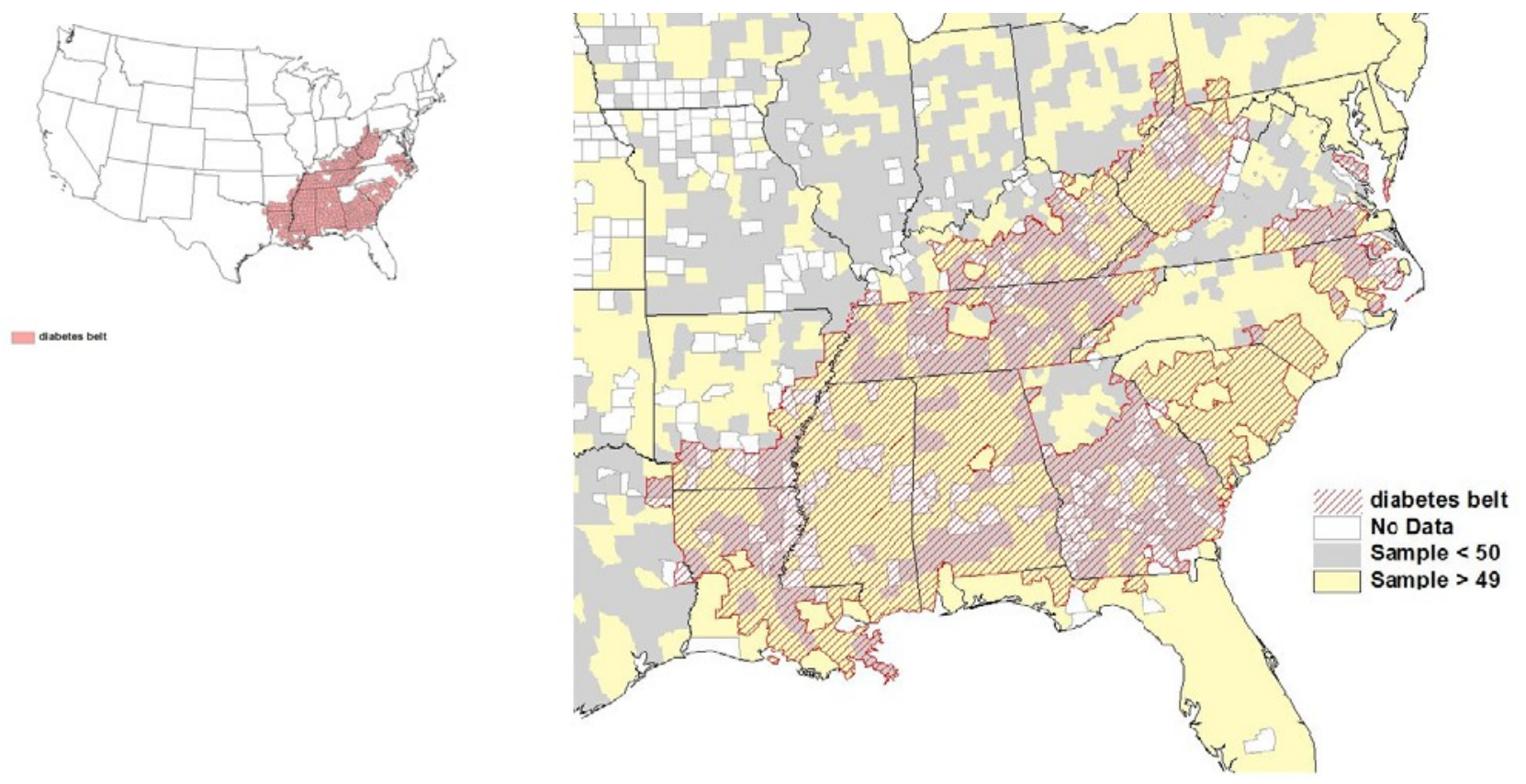

Note: (Left) Barker et al.'s diabetes belt (2011, Figure 2, p. 437); (Right) Areas with good, sparse, or no 2007-2008 BRFSS data used in deriving Barker et al.’s diabetes belt. 
Carolina data are more reliable, because the state systematically oversamples to yield at least 50 sample respondents in each county, so the existence of a diabetes belt there is more credible.

Barker et al (2011) use BRFSS survey data to demonstrate areas of greatest need, using methods designed to deal with the sparse information from surveys and to extrapolate via smoothing methods to provide some mapped patterns describing needy areas (Barker et al., 2011; CDC, 2009). When using smoothing approaches for mapping, data are often pooled across years to increase sample sizes in counties and fill in data for missing counties (Jia et al., 2004; Pickle \& Su, 2002). The county-level estimates mapped in the Barker et al. (2011) study were based on a small area estimation approach that employs a statistical model that "borrowsstrength" in making an estimate for each county by using data collected in other counties nearby. More specifically, the estimates of diagnosed diabetes prevalence for all counties were spatially smoothed using a Bayesian model with a conditional autoregressive prior that is useful for mapping smoothed estimates of the outcome (CDC, 2009; Wakefield, Best, \& Waller, 2000). In this modeling approach, the county outcome estimates are smoothed versions of multicounty clusters formed from observed outcome values in adjacent counties, irrespective of whether adjacent counties were actually similar in their observed diabetes prevalence, and ignoring other factors.

Geographic smoothing algorithms such as the one used by Barker et al. (2011) that borrow information from neighboring areas stabilize results from sparsely populated areas, reducing variability in the data, but increase the bias in the estimates for each small area (Pickle \& Su, 2002). Thus, smoothing produces a more pronounced pattern at the regional level, such as the diabetes belt depicted in Barker et al.'s Figure 2 (reproduced in Exhibit 1, above). However, the proportions predicted for any particular county by this sort of map smoothing algorithm should not be interpreted as county-level estimates by the viewer (Pickle \& Su, 2002).
It is not widely known the degree to which overgeneralized conclusions from studies using BRFSS survey data might be misleading, because the spatially representative population counterfactual is absent. We know of only one published study that examines performance of the BRFSS at the substate (county) level using a valid counterfactual study population. Jia et al. (2004) examined data from the year 2000 to compare prevalence of disability in U.S. Census data (the population data set) with BRFSS survey sample data. They found that the BRFSS represented the nation and individual states well, which it was designed to do. However, the BRFSS did a poor job representing counties, primarily because 2,615 of 3,117 (nearly $84 \%$ ) counties had less than 50 observations in the year 2000 BRFSS survey sample.

In summary, not all data that contain geographic address identifiers are considered spatially representative, hence they are not spatially sufficient data. Many surveys conducted in the United States, for example by the Bureau of Labor Statistics or the National Centers for Health Statistics, do not provide spatially representative data at small scales. Spatially representative demographic data are defined as data which are available at the geographic level at which they fully represent that area's population. US Census data are fully representative of households at the census tract level, but not at the block group level. Why is this? This is a result of address swapping among households within census tracts, to jumble their locations across census block groups and blocks, in order to preserve privacy for householders. The block or block-group data reported by the Census do not necessarily represent the households in those geographic areas, and are not spatially representative at the block or block group level.

\section{The Importance of Spatial Data in Social Sciences Research}

Although the role of 'place' in human health has been recognized for a long time, studies focusing on public health have mostly concentrated on the person and time, with little consideration of the 
contribution of place (Susser \& Susser, 1996). When place is considered, the most commonly used measures are socioeconomic (poverty, education) or racial composition in the area of study (Osypuk and Acevedo-Garcia, 2010; Acevedo-Garcia et al, 2008). Other variables describing a person's spatial interaction with others and the environment are usually ignored, due to limited knowledge of available data sources or analytic resources to merge them from different sources or to create new measures. Inconsistencies in findings across studies are sometimes blamed on use of different measures reflecting the same underlying construct, among other things.

One of the essential components that can help in understanding disparities in human outcomes is the identification of place-specific factors. These so-called contextual factors include sociodemographic, economic, political, ecological, behavioral, and environmental variables. Information on these variables can be collected at micro, macro, or intermediary levels, or aggregated from individual-level surveys into larger area levels. Several recent papers have focused on multiple levels of influence impacting health outcomes (Osypuk and Acevedo-Garcia, 2010; Acevedo-Garcia et al, 2008). Osypuk and Acevedo-Garcia (2010) argue that regional influences related to economic opportunities at a scale broader than the immediate neighborhood or social community are important determinants of disparities in health outcomes.

Although contextual factors data have become more available recently, many of these data are limited to macro or intermediary level (e.g., state, metropolitan area, county from sources such as the Area Resource File (ARF). Factors that require analytical derivation from micro-level data (e.g. area income dispersion index, land use mix index, index of social diversity, social capital index, $100 \%$ population-based cancer screening rates, measures of market concentration or competition, distance to providers or other access measures) are less widely available. Also, measures requiring complex computational algorithms are subject to data errors, and when these measures are created independently by each research team, a proliferation of different sources of measurement error may occur. Thus, results from various studies are less comparable because of data errors or other factors that reduce comparability, such as use of different algebraic expressions, units, or functional forms or data with different geospatial or time coverage (Schad et al, 2011).

\section{Availability of a Comprehensive Set of Spatially Representative Data}

The Spatial Impact Factor Database and the web services available for mapping, downloading, and searching it were supported by a grant from the National Institutes of Health to support work at RTI International and Arizona State University. Web links for downloading the SIFD and user documentation can be accessed through the project websites (https://rtispatialdata.rti.org; http://geodacenter.asu.edu/projects/rti). Given the definition and examples of spatially representative data above, it is clear that the SIFD contains spatially- representative data, and is thus a reliable spatial data resource. The SIFD provides a comprehensive set of geospatial factors merged together in a single database for each geographic scale, which is convenient and can reduce the need for duplicative efforts while providing conformity in measurement or processing errors across studies using the same database. It provides a consistent source of reliable, high quality measures characterizing contextual environments in which people live, and is provides full metadata documentation for each variable (original source and date, units of measurement, detailed algorithms used to develop complex measures, special considerations or caveats).

The main purpose for developing the SIFD was to provide to the research community a comprehensive set of geospatial variables, reflecting social, physical, natural, economic, and other dimensions of the socio-ecological environment, at various spatial scales. Most demographic and health disparities research to date includes only a limited set of contextual 
factors, mainly measures of socioeconomic conditions or population proportions by race or ethnicity. Because recent thought leaders stress the importance of a variety of factors operating at many levels of influence, our goal was to provide readily-accessible spatial data for a comprehensive group of variables.

The first step in designing the database was to develop a conceptual model that could guide us regarding what to include in the database, and at which geographic levels. All variables were considered to represent meaningful spatial impact factors to use as explanatory variables in empirical research on health or other social science outcomes. We focused initially on conceptual modeling of the processes leading to health behaviors, healthcare utilization, and healthcare outcomes. We searched the literature for conceptual models of socio-ecological processes and blended several into a hybrid construct. The conceptual model that we used to guide development of the database contents (Exhibit 2) describes spatial interaction among people and characteristics of their contextual environments along the pathways to healthcare utilization, allowing for multiple levels of influence, which we describe in detail elsewhere (Mobley et al, 2008; 2010; 2012). This is a hybrid model that incorporates the classic behavioral model of utilization (Aday\& Andersen, 1974) and a model of spatial interactions in health care access and utilization (Khan \& Bhardwaj, 1994). The series of nested and overlapping boxes in the diagram are intended to represent the interactions at various geographic scales and among various sets of factors with people along the various pathways to population health outcomes.

This conceptual model is consistent with a historical topic in the epidemiology literature which advocated "eco-epidemiology" as a useful new paradigm for modern epidemiological research (Susser \& Susser, 1996). This paradigm views the individual as existing within a set of nested constructs, where each level is part of a broader system and interacts with those above and below it. The eco-epidemiological paradigm was subsequently embraced in applied public health research through the constructs of multilevel modeling (Susser \& Susser, 1996; Bronfenbrenner, 1979; Sallis, Bauman \& Pratt, 1998; Sallis \& Owen, 1999; Sallis, Owen \& Frank, 2000; Baranowski, Anderson \& Carmack, 1998; Smedley \& Syme, 2000; Schmid, Pratt \& Witmer, 2006; Schulz et al, 2005; Blakely \& Woodward, 2000; Duncan, Jones \& Moon, 1996; 1998; DiezRoux, 1998; Krieger 1994).

In the model presented in Exhibit 2, which we have used to study cancer screening and stage at diagnosis (Mobley et al, 2008; 2010; 2012; Kuo, Mobley \& Anselin, 2011), each of the states in the US might represent a semi-autonomous macrolevel healthcare environment with unique and decentralized cancer control programs, regulatory environments, insurance laws, and political environments that are state-specific and varied across the landscape. Within the states, state healthcare environments are governed by local and regional politics, social systems, and market level forces that determine supply factors, and community or neighborhood-level forces that determine social or demand factors. Individuals exhibit predisposing, enabling, and need characteristics which interact with the forces in the broader system. These different forces and levels of influence are reflected in the conceptual model represented in Exhibit 2.

Resonant with the conceptual model, the SIFD encompasses a comprehensive set of geospatial variables, reflecting social, physical, natural, economic, built, and other dimensions of the socio-ecological environment, at various spatial scales. The database includes as many geographic levels and time periods as were possible, based on availability of existing spatially representative data for each geographic level. We focused for the most part on publicly available data that could be easily obtained, and supplemented this with a number of calculated variables that were both time and resource intensive. Several cross-sectional data sets at different time periods have been included, from 1960-2009, for data available in multiple periods. An overview and description of all data elements available in Version 4 is provided in Table 1. 
Exhibit 2. Socio-Ecological Model of Health Behaviors, Health Services Utilization, and Health Outcomes

Macro/Fundamental or Distal Factors: Distribution of: Wealth, Educational Opportunities, and Political Influence; Social and Economic Policies, Institutions, Regulations, Topography, Climate, Supply of Natural Resources

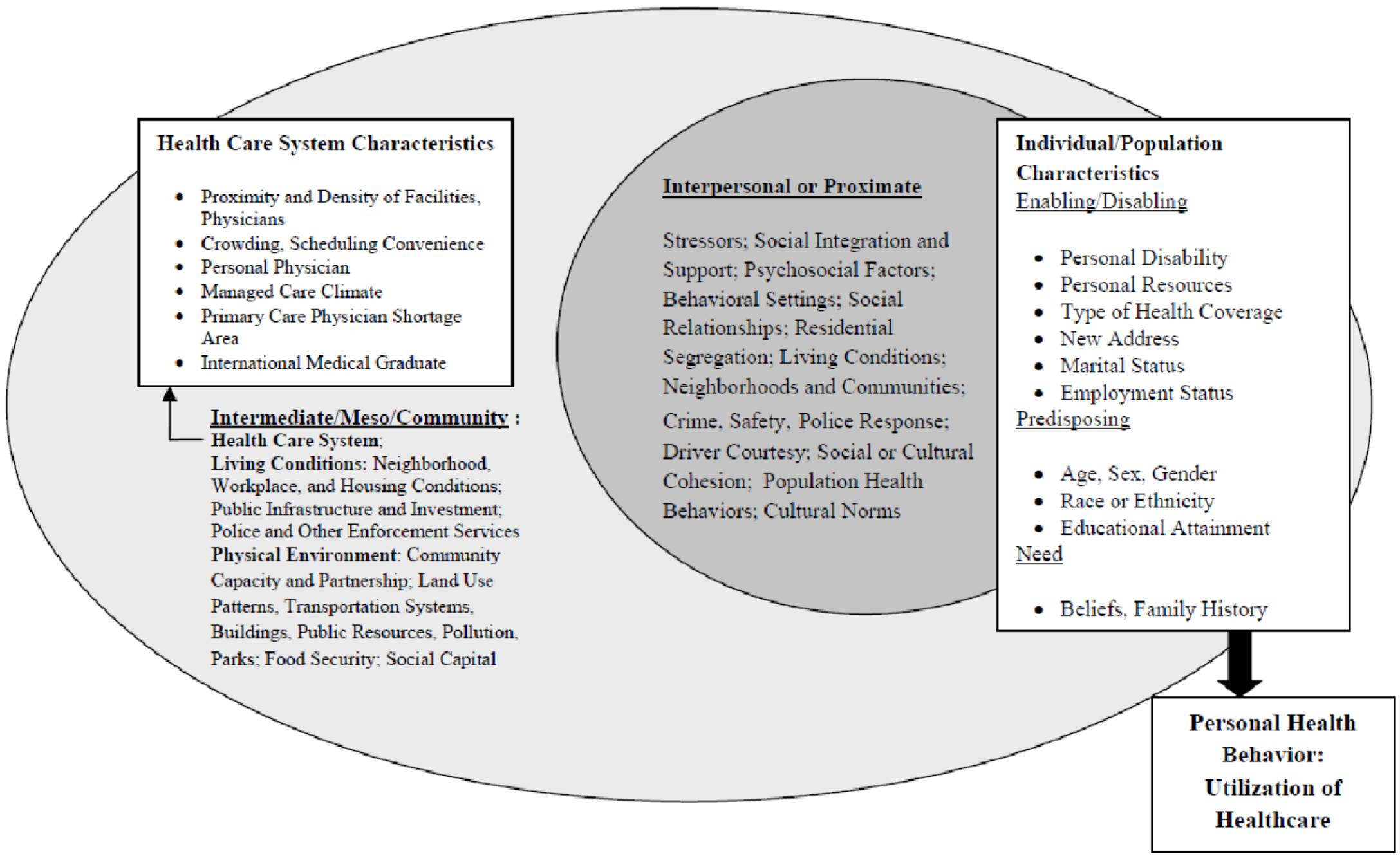


Table 1. Overview Description of All Data Available in SIF Version 4

\begin{tabular}{|c|c|c|c|c|}
\hline Source & Variable Count & Data Years & Geography-levels & Description \\
\hline \multicolumn{5}{|c|}{ U.S. Census Data } \\
\hline \multicolumn{5}{|c|}{ U.S. Census Summary Files and Estimates } \\
\hline & 412 Variables & 2000 & $\begin{array}{l}\text { county, PCSA, } \\
\text { ZCTA, tract, } \\
\text { MSSA }\end{array}$ & $\begin{array}{l}\text { pulled from } 2000 \text { U.S. Census Summary Files; } \\
\text { summarized from ZCTA to PCSA }\end{array}$ \\
\hline & 282 Variables & 2000 & $\begin{array}{l}\text { county, PCSA, } \\
\text { ZCTA, tract, } \\
\text { MSSA }\end{array}$ & $\begin{array}{l}\text { calculated from } 2000 \text { U.S. Census Summary File data; } \\
\text { summarized from ZCTA to PCSA }\end{array}$ \\
\hline & 262 Variables & 1990 & $\begin{array}{l}\text { county, PCSA, } \\
\text { ZCTA, tract }\end{array}$ & $\begin{array}{l}\text { pulled from } 1990 \text { U.S. Census Summary Files or } \\
\text { calculated to match } 2000 \text { Census variables (1990 zip } \\
\text { codes cross-walked to } 2000 \text { ZCTAs to get comparable } \\
\text { values); summarized from ZCTA to PCSA }\end{array}$ \\
\hline & 69 Variables & 1990 & $\begin{array}{l}\text { county, PCSA, } \\
\text { ZCTA, tract }\end{array}$ & $\begin{array}{l}\text { calculated from } 1990 \text { U.S. Census summary File data; } \\
\text { summarized from ZCTA to PCSA }\end{array}$ \\
\hline & 16 Variables & $2000-2008$ & county only & Census estimates of Population (all and elderly) \\
\hline & 3 Variables & 1990 & county only & Counts of RNs, LPNs, and physicians assistants \\
\hline \multicolumn{5}{|c|}{ U.S. Census Bureau Small Area Income \& poverty estimates } \\
\hline & 36 Variables & $\begin{array}{l}1989,1995,2000 \\
2005\end{array}$ & county only & poverty and income estimates by county \\
\hline \multicolumn{5}{|c|}{ U.S. Census Bureau, Small Area Health Insurance Estimates } \\
\hline & 10 Variables & 2000 & county only & health insurance status estimates by county \\
\hline \multicolumn{5}{|c|}{ Metropolitan and Micropolitan Statistical Areas } \\
\hline & 9 Variables & December 2003 & county only & statistical area names and codes \\
\hline \multicolumn{5}{|c|}{ RTI derived data from U.S. Census data and Penn State Social Capital Index } \\
\hline \multicolumn{5}{|c|}{ Social Segregation Measures } \\
\hline & 26 Variables & 1990 and 2000 & $\begin{array}{l}\text { county, PCSA, } \\
\text { MSSA }\end{array}$ & $\begin{array}{l}\text { Isolation Index, Interaction Index, Diversity Index, Index } \\
\text { of Spatial Proximity, and White's Clustering Measure }\end{array}$ \\
\hline \multicolumn{5}{|c|}{ Income Disparity Measures } \\
\hline & 14 Variables & 1990 and 2000 & county only & $\begin{array}{l}\text { Gini Coefficient, Atkinson's Measure, Coefficient of } \\
\text { Variation, Entropy Index, Ricci-Schutz Coefficient, and } \\
\text { Theil's Entropy Index }\end{array}$ \\
\hline \multicolumn{5}{|c|}{ Household Income Dispersion } \\
\hline & 4 Variables & 1990 and 2000 & $\begin{array}{l}\text { county, PCSA, } \\
\text { ZCTA, tract, } \\
\text { MSSA }\end{array}$ & $\begin{array}{l}\text { household income dispersion for all households and } \\
\text { households with householder } 65+\end{array}$ \\
\hline \multicolumn{5}{|c|}{ Social Capital Data and Index } \\
\hline & 54 variables & $1990,1997,2005$ & county & $\begin{array}{l}\text { Rupasingha, Anil and Stephan J. Goetz, "US County- } \\
\text { Level Social Capital Data, 1990-2005." The Northeast } \\
\text { Regional Center for Rural Development, Penn State } \\
\text { University, University Park, PA, 2008. } \\
\text { http://nercrd.psu.edu/Social Capital/index.html }\end{array}$ \\
\hline \multicolumn{5}{|c|}{ Health Resources and Services Administration (HRSA) Spatial Data Warehouse } \\
\hline \multicolumn{5}{|c|}{ Physicians and other healthcare staff or facilities } \\
\hline & 113 Variables & $1999-2001 ; 2006$ & $\begin{array}{l}\text { PCSA, ZCTA, } \\
\text { MSSA) }\end{array}$ & $\begin{array}{l}\text { counts of physicians and physician assistants by various } \\
\text { categories; RTI summarized from ZCTA to MSSA (AMA } \\
\text { Masterfile) }\end{array}$ \\
\hline \multicolumn{5}{|c|}{ Population related } \\
\hline & 140 Variables & 2000 & PCSA and ZCTA & $\begin{array}{l}\text { population counts by various categories as well as } \\
\text { poverty, housing, and income data }\end{array}$ \\
\hline \multicolumn{5}{|c|}{ Patient/Medicare beneficiary } \\
\hline & 204 Variables & $1999 ; 2005$ & $\begin{array}{l}\text { PCSA, ZCTA, } \\
\text { MSSA }\end{array}$ & $\begin{array}{l}\text { beneficiary information related to reimbursements, visits, } \\
\text { hospitalizations, and deaths; RTI summarized from ZCTA } \\
\text { to MSSA ( } 100 \% \text { CMS denominator files, MEDPAR, } \\
\text { carrier, and outpatient claims) }\end{array}$ \\
\hline \multicolumn{5}{|c|}{ Bureau of Primary Health Care } \\
\hline & 7 Variables & $\begin{array}{l}1998 ; 2000-2004 \\
2007\end{array}$ & county only & Health Professional Shortage Area (HPSA) codes \\
\hline \multicolumn{5}{|c|}{ crosswalk for nested geographies } \\
\hline & 1 Variables & 2000 & PCSA and ZCTA & PCSA/ZCTA crosswalk \\
\hline \multicolumn{5}{|c|}{ Centers for Medicare and Medicaid (CMS) } \\
\hline & 77 Variables & $1999-2005$ & county only & $\begin{array}{l}\text { Medicare eligibles and enrollees, payment rates, and } \\
\text { penetration ratio information compiled by RTI }\end{array}$ \\
\hline & 84 variables & $2001-2006$ & PCSA, ZCTA, & $100 \%$ FFS population utilization rates for mammography, \\
\hline
\end{tabular}


Table 1. Overview Description of All Data Available in SIF Version 4 (Cont'd)

\begin{tabular}{|c|c|c|c|c|}
\hline Source & Variable Count & Data Years & Geography-levels & Description \\
\hline & & & county, MSSA & $\begin{array}{l}\text { colonoscopy, sigmoidoscopy; Herfindahl indices for these } \\
3 \text { provider types; counts of these } 3 \text { provider types by } \\
\text { unique UPIN; distance to closest provider by type }\end{array}$ \\
\hline & 234 variables & $2001-2006$ & $\begin{array}{l}\text { PCSA, ZCTA, } \\
\text { county, MSSA }\end{array}$ & $\begin{array}{l}100 \% \text { FFS population utilization rates for mammography, } \\
\text { colonoscopy, sigmoidoscopy; by race or ethnicity }\end{array}$ \\
\hline & 180 variables & $2001-2006$ & $\begin{array}{l}\text { PCSA, ZCTA, } \\
\text { county, MSSA }\end{array}$ & $\begin{array}{l}\text { Area proportion of Medicare eligibles by insurance } \\
\text { coverage type (Part A, Part B, dually eligible, Medicare } \\
\text { HMO) }\end{array}$ \\
\hline \multicolumn{5}{|c|}{ Employment, Unemployment, Income, Assistance, and Food Security } \\
\hline & 20 Variables & $2000-2004$ & county only & $\begin{array}{l}\text { employment and labor force information (Current } \\
\text { Population Survey) }\end{array}$ \\
\hline & 58 Variables & $\begin{array}{l}1969-2007 ; 1990- \\
2008\end{array}$ & county only & $\begin{array}{l}\text { Unemployment rate 1990-2008 (Bureau Labor Statistics) } \\
\text { Per Capita Income 1969-2007 (Bureau of Economic } \\
\text { Analysis) }\end{array}$ \\
\hline & 9 variables & $\begin{array}{l}\text { 1993-1995; 1997- } \\
1999 ; 2000-2004 \\
2009\end{array}$ & county only & Number of food stamp recipients \\
\hline & 58 variables & $\begin{array}{l}2006-2008 \text { for } \\
\text { establishments; } 2000 \\
-2002 \text { for household } \\
\text { data }\end{array}$ & county only & $\begin{array}{l}\text { Food atlas data from USDA: } \\
\text { http://ers.usda.gov/foodatlas/downloadData.htm } \\
\text { Proximity to stores and restaurants, expenditures per } \\
\text { capita on food by type; \# SNAP enrollees and benefits }\end{array}$ \\
\hline \multicolumn{5}{|c|}{ National Cancer Institute's Surveillance Epidemiology and End Results (SEER) } \\
\hline & 5 Variables & $1990-2006$ & county only & $\begin{array}{l}\text { cost of living index, crowding, and contract health service } \\
\text { delivery area }\end{array}$ \\
\hline \multicolumn{5}{|c|}{ Nielsen, François and Arthur S. Alderson } \\
\hline & 3 Variables & 1970,1980 , and 1990 & county only & $\begin{array}{l}\text { GINI coefficients of income inequality for } 1970,1980 \text {, } \\
\text { and } 1990\end{array}$ \\
\hline \multicolumn{5}{|c|}{ Crime Statistics } \\
\hline \multicolumn{5}{|c|}{ FBI's Uniform Crime Reporting Program } \\
\hline & 270 Variables & $2000-2005$ & county only & county-level detailed arrest and offense data \\
\hline \multicolumn{5}{|c|}{ An Atlas of the Spatial Patterning of County-Level Homicide } \\
\hline & 60 Variables & $1960-1990$ & county only & 1960-1990 - National Consortium on Violence Research \\
\hline \multicolumn{5}{|c|}{ Toxins in Air, Water, and Soil } \\
\hline \multicolumn{5}{|c|}{ EPA Air Quality Systems (AQS) } \\
\hline & 1080 Variables & $1990-2006$ & $\begin{array}{l}\text { county only } \\
\text { (limited counties) }\end{array}$ & $\begin{array}{l}\text { monthly median air concentrations for } \mathrm{CO}, \text { Lead, } \mathrm{NO} 2 \text {, } \\
\text { Ozone, } \mathrm{PM} 10 \text {, and } \mathrm{SO} 2\end{array}$ \\
\hline \multicolumn{5}{|c|}{ EPA's 1999 National-scale Air Toxins Assessment } \\
\hline & 148 Variables & 1999 & county only & $\begin{array}{l}\text { hazard quotients and cancer risk of various air toxins by } \\
\text { county }\end{array}$ \\
\hline \multicolumn{5}{|c|}{ National Water Information System (NWIS) } \\
\hline & 90 Variables & $1995-2005$ & $\begin{array}{l}\text { county only } \\
\text { (limited counties) }\end{array}$ & $\begin{array}{l}3 \text { year running average water concentrations of arsenic, } \\
\text { cadmium, lead, mercury, selenium, and zinc }\end{array}$ \\
\hline \multicolumn{5}{|c|}{ EPA Map of Radon Zones } \\
\hline & 1 Variable & 2008 correspondence & county only & average indoor Radon screening level by zones \\
\hline \multicolumn{5}{|c|}{ Transportation Impedance and Land Use } \\
\hline \multicolumn{5}{|c|}{ Transportation Impedance Data } \\
\hline & 5 Variables & 1990 and 2000 & tract only & $\begin{array}{l}\text { workers entering/leaving tract, and rural urban } \\
\text { commuting area (RUCA) codes }\end{array}$ \\
\hline \multicolumn{5}{|c|}{ NHD Plus's National Elevation Dataset (NED) } \\
\hline & 3 Variables & 2006 & tract, county & $\begin{array}{l}\text { Minimum elevation in area (tract with lowest elevation); } \\
\text { maximum elevation in area; average elevation in area }\end{array}$ \\
\hline \multicolumn{5}{|c|}{ PRISM Group - Oregon State University-climate data } \\
\hline & 144 Variables & $2000,2005,2007$ & $\begin{array}{l}\text { county and Census } \\
\text { tract }\end{array}$ & $\begin{array}{l}\text { monthly average minimum/maximum temperatures, dew } \\
\text { points, and precipitation }\end{array}$ \\
\hline \multicolumn{5}{|c|}{ Economic Research Service, US Department of Agriculture } \\
\hline & 20 Variables & $1993,2000,2003$ & county only & rural/urban measures \\
\hline \multicolumn{5}{|c|}{ Land Use based on USGS coverage } \\
\hline & 1 Variable & 2001 & $\begin{array}{l}\text { county, PCSA, } \\
\text { ZCTA }\end{array}$ & $\begin{array}{l}\text { RTI calculated land use mix entropy index, which varies } \\
\text { from } 0 \text { (homogenous land use) to } 1 \text { (most mixed land use) }\end{array}$ \\
\hline
\end{tabular}


The SIFD provides numeric data combined from multiple sources and multiple time periods, defined for multiple levels of geography (census tract, ZCTA, county, PCSA, and MSSA). The SIFD includes only 'spatially representative' data elements, representing entire populations, subgroups, or measurements of things, in all areas of the US. No modeled, interpolated, kriged, or Bayesian small area estimates are included in the database. (One exception is the EPA's Air Toxics Inventory data, which are modeled data from EPA collection sites; full metadata describing the modeling is provided as part of the metadata in the SIFD). When observations in the database appear to be blank, this signifies that no data or measurements were actually available for that time and place. Blanks where data are missing are NOT filled with zeros. This is an important aspect of quality control that we provide throughout the database. Exceptions are noted in the metadata, where blanks filled with zeros were obtained from the prime source of data (e.g. crime data with zeros filled for the entire states of Florida and Illinois).

The SIFD includes calculated measures of residential segregation by race or ethnicity in several dimensions; a land use mix index reflecting urban sprawl; some modeled data provided by the Environmental Protection Agency on toxins in air/soil/water (which may contain interpolation errors beyond our control); data describing SES, income disparity, cost of living, and health insurance; data describing transportation congestion factors, climate, and topography; a social capital index for three years spanning 1990-2005; food security data, and many other measures reflecting social cohesion or support from US Census data. Perhaps of greatest interest to practitioners, cancer control planners, and researchers is the small-area screening rates data that were developed from 100\% Medicare claims files. These screening variables are for breast or colorectal cancer screening utilization among FFS Medicare beneficiaries for each year 2001-2006.

The SIFD is a freely available, comprehensive set of socio-ecological and environmental variables, useful in characterizing the contextual environments in which people live. All items distributed in the public use database have met data user restrictions and privacy protection protocols whenever these exist. No data will be distributed that violate personal privacy, licensing, or data use agreement restrictions or requirements. This resource represents spatially representative data that can be combined with other sources for research in spatial demography.

\section{Acknowledgments}

This work was supported by a National Cancer Institute grant (1Ro1CA126858) and an American Recovery and Reinvestment Act (ARRA) supplement to it. The content is solely the responsibility of the authors and does not necessarily represent the official views of RTI International, Arizona State University, the National Cancer Institute, or the National Institutes of Health.

\section{References}

Acevedo-Garcia, D., Osypuk, T. L., McArdle, N., \& Williams, D. R. (2008). Toward a policy- relevant analysis of geographic and racial/ethnic disparities in child health. Health Affairs (Project Hope), 27(2), 321-333.

Aday, L. A., \& Andersen, R. (1974). A framework for the study of access to medical care. Health Services Research, 9, 208-220.

Baranowski T, Anderson C, Carmack C: Mediating variable framework in physical activity interventions: How are we doing? How might we do better? Am J Prev Med 1998, 15:266-97.

Barker, L. E., Kirtland, K. A., Gregg, E. W., Geiss, L. S., \& Thompson, T. J. (2011, April). Geographic distribution of diagnosed diabetes in the U.S.: A diabetes belt. American Journal of Preventive Medicine, 4O(4), 434-439. PubMed PMID: 21406277.

Blakely T, Woodward A: Ecological effects in multilevel studies. $J$ Epidemiol Community Health 2000, 54:367-374.

Bronfenbrenner $\mathrm{U}$ : The Ecology of Human 
Development. Experiments by Nature and Design Cambridge, Massachusetts: Harvard University Press; 1979.

Centers for Disease Control and Prevention (CDC). (2009, November 20). Estimated county- level prevalence of diabetes and obesity, United States, 2007. Morbidity and Mortality Weekly Report, 58(45),1259-1263. Available at: http://www.cdc.gov/ mmwr/preview/mmwrhtml/mm5845a2.htm.

Centers for Disease Control and Prevention (CDC). (2012). Centers for Disease Control and Prevention: National Diabetes Surveillance System. Available at: http://apps.nccd.cdc.gov/DDTSTRS/default.aspx.

Diez-Roux A: Bringing context back into epidemiology: Variables and fallacies in multilevel analysis. $A m J$ Public Health 1998, 88:216-222.

Duncan C, Jones K, Moon G: Context, composition, and heterogeneity: using multilevel models in health research. Soc Sci Med 1998, 46:97-117.

Duncan C, Jones K, Moon G: Health-related behavior in context: a multilevel modeling approach. Soc Sci Med 1996, 42:817-830.

Frazier, E. L., Franks, A. L., \& Sanderson, L. M. (1992). Using Behavioral Risk Factor Surveillance data. In Using chronic disease data: A handbook for public health practitioners. Atlanta GA: Centers for Disease Control and Prevention.

Jia, H., Muennig, P., \& Borawski, E. (2004). Comparison of small-area analysis techniques for estimating county-level outcomes. American Journal of Preventive Medicine, 26(5), 453-460.

Khan, A. A., \& Bhardwaj, S. M. (1994). Access to health care: A conceptual framework and its relevance to health care planning. Evaluation \& the Health Professions, 17, 60-76.

Krieger N: Epidemiology and the web of causation: has anyone seen the spider? Soc Sci Med 1994, 39:887903 .

Kuo, T. , and Mobley, L., and Anselin, L., "Geographic Disparities in Late-Stage Breast Cancer Diagnosis in California”, Health\&Place, $v 17$ (2011) 327-334.

Mobley, L., Kuo, M., Urato, M., Subramanian, S., Watson, L., and Anselin, L.,"Spatial Heterogeneity in
Cancer Control Planning and Cancer Screening Behavior" forthcoming in the 2012 Special Issue on the Geography of Health in the Annals of the Association of American Geographers (special issue September 2012).

Mobley, L., Kuo, T., and Urato, M., and Subramanian, S.,(2010) "Community contextual predictors of endoscopic colorectal cancer screening in the USA: spatial multilevel regression analysis", International Journal of Health Geographics, 2010, 9:44.

Mobley, L.R., T. Kuo, and L.S. Andrews. (2008). How Sensitive are Multilevel Regression

Findings to Defined Area of Context? A Case Study of Mammography Use in California.

Medical Care Research and Review, v 65, pp 315-337; PMID: 18259047

Osypuk , T. and Acevedo-Garcia , D. 2010. Beyond individual neighborhoods: A geography of opportunity perspective for understanding racial/ethnic health disparities, Health\&Place. Doi:10.1016/j.healthplace. 2010.07.002

Pickle, L., \& Su, Y. (2002). Within-state geographic patterns of health insurance coverage and health risk factors in the United States. American Journal of Preventive Medicine, 22(2), 79.

Sallis J, Bauman A, Pratt M: Environmental and policy interventions to promote physical activity. Am J Prev Med 1998, 15:379-97.

Sallis J, Owen N, Frank L: Behavioral epidemiology: a systematic framework to classify phases of research on health promotion and disease prevention. Ann Behav Med 2000, 22:294-8.

Sallis J, Owen N: Physical Activity and Behavioral Medicine. Thousand Oaks, CA: Sage; 1999.

Schad, P., Mobley, L., and Hamilton, C. (2011)"Building a Biomedical Cyberinfrastructure for Collaborative Research", American Journal of Preventive Medicine , Supplement: Cyberinfrastructure for Consumer Health, v 4O(5S2) (AMEPRE_3067), S144-S150.

Schmid T, Pratt M, Witmer L: A framework for physical activity policy research. $J$ Phys Act Health 2006, 3(Suppl 1):S2O-S29. 
Schulz A, Kannan S, Dvonch J, Israel B, Allen A, James S, House J, Lepkowski J: Social and physical environments and disparities in risk for cardiovascular disease: the healthy environments partnership conceptual model. Environ Health Perspect 2005, 113:1817-1825.

Smedley B, Syme S (Eds): Promoting Health: Strategies from Social and Behavioral Research. Institute of Medicine, Washington DC: National Academies Press; 2000.
Susser M, Susser E: Choosing a future for epidemiology: from black box to Chinese boxes and eco-epidemiology. Am J Public Health 1996, 86:674677.

Wakefield, J. C., Best, N. G., \& Waller, L. A. (2000). Bayesian approaches to disease mapping. In P. Elliott, J. C. Wakefield, N. G. Best, \& D. J. Briggs (Eds.), Spatial epidemiology. New York, NY: Oxford University Press. 